\begin{tabular}{|l|l|l||}
\hline \multicolumn{2}{|c|}{ PublisherInfo } \\
\hline \hline PublisherName & $:$ & BioMed Central \\
\hline \hline PublisherLocation & $:$ & London \\
\hline \hline PublisherImprintName & $:$ & BioMed Central \\
\hline \hline
\end{tabular}

\title{
Thyroxine in ARF
}

\begin{tabular}{|l|l|l||}
\hline \multicolumn{2}{|c||}{ ArticleInfo } \\
\hline \hline ArticleID & $:$ & 4193 \\
\hline \hline ArticleDOI & $:$ & $10.1186 /$ ccf-2000-4857 \\
\hline \hline ArticleCitationID & $:$ & 4857 \\
\hline \hline ArticleSequenceNumber & $:$ & 52 \\
\hline \hline ArticleCategory & $:$ & Paper Report \\
\hline \hline ArticleFirstPage & $:$ & 1 \\
\hline \hline ArticleLastPage & $:$ & 4 \\
\hline \hline & & RegistrationDate : 2000-4-17 \\
\hline ArticleHistory & $:$ & OnlineDate \\
\hline ArticleCopyright & $:$ & Current Science Ltd2000-17 \\
\hline \hline ArticleGrants & $:$ & \\
\hline \hline ArticleContext & $:$ & 1305422 \\
\hline \hline
\end{tabular}




\section{Keywords}

Acute renal failure, thyroxine

\section{Comments}

This is an excellent study conducted to the highest standards. The small size of the trial reduces its statistical power, but clearly its premature cessation was essential. In addition to the authors' explanations for the observed differences between the human and animal studies, the issue of the optimal timing of initiation of thyroid hormone therapy in animal models, within the effective window, is underplayed. Yet again, promising animal studies have proven to be poor predictors of clinical reality, raising the issue of the value of continuing such research. This study, together with the recent growth hormone trial, demonstrates that endocrine biochemical abnormalities in the critically ill do not necessarily represent pathophysiology but may in fact be a useful adaptive physiological response.

\section{Introduction}

Thyroid hormone replacement has been shown to be effective in promoting recovery from acute renal failure (ARF) in a number of ischaemic and toxic animal models. In these models renal injury was induced, followed by administration of either a single dose or a short course of supraphysiological doses of thyroxine. There was no clinical or biochemical evidence of hyperthyroidism in these test animals. An uncontrolled trial of thyroxine in paediatric patients with ARF provoked a diuresis in all patients. It is well documented that euthyroid sick syndrome is common in acutely ill patients. The significance of this finding is conjectural and the value of thyroid replacement is unknown. To date, there has not been a trial of thyroxine in adult patients with ARF, but trials of thyroxine in acutely ill subjects have been inconclusive. These small trials demonstrated neither benefit nor detriment.

\section{Aims}

To determine whether thyroxine altered the course or mortality associated with ARF. 


\section{Methods}

Study design was that of a prospective, randomised, placebo-controlled, double-blind trial conducted in a single teaching hospital intensive care unit (ICU). ARF was defined as a doubling of serum creatinine within a $24 \mathrm{~h}$ period. Patients with prerenal, obstructive or obstetrically related ARF were excluded, along with patients with acute glomerulonephritis, interstitial nephritis, hepatorenal syndrome or New York Heart Class IV. All patients were clinically euthyroid. Patients in the treatment arm received $150 \mu \mathrm{g}$ of thyroxine intravenously every $12 \mathrm{~h}$ for $48 \mathrm{~h}$. Outcome measures were in-hospital mortality and severity of renal failure. Patients requiring renal replacement therapy received either intermittent haemodialysis or continuous venovenous haemodialysis dependant on a clinical protocol. The study was powered to detect a 33\% difference in mortality based on a retrospective analysis of mortality in ICU-acquired ARF.

\section{Results}

The trial was stopped after 59 patients had been recruited (original target was 97), as a result of a significantly higher mortality in the thyroxine group. Demographic and physiological data were comparable between the two groups. The aetiology of ARF was reasonably well matched. Thyroid function tests at day 0 were universally compatible with the euthyroid sick syndrome. The thyroxine patients demonstrated a fall in thyroid stimulating hormone (TSH) levels at days 1 and 7 , whereas the control group showed a rise in TSH, which reached significance at day 7. There was no significant difference in the severity of, or recovery from, ARF. Mortality in the control group was 4 out of 28 $(13 \%)$, whereas the mortality of the thyroxine group was 12 out of $31(43 \%)$. Time to death from study entry was comparable. The only factor that correlated with death amongst all the patients was day 1 TSH level. However, the survivors and non-survivors had markedly different TSH profiles, the survivors having a high level which rose, the non-survivors having a low level which didn't change. Steroid and dopamine use was the same in both groups and between survivors and nonsurvivors.

\section{Discussion}

This study demonstrates that patients with ARF exhibit biochemical evidence of the euthyroid sick syndrome. Supraphysiological doses of thyroxine in these patients induced no evidence of hyperthyroidism but appeared to be associated with a poorer outcome, suggesting that these patients should not receive such therapy. In contrast to published studies of animal models, there was no effect on the course of ARF. There have been similar findings in human clinical trials of insulin-like growth factor and atrial natriuretic peptide, which showed similar promise in animal models of ARF. In the animal trials, thyroxine was only effective after the ARF inducing insult, and only for the first $24 \mathrm{~h}$. In this study, the initiation of therapy may have been after this therapeutic window. Other possible 
explanations for the discrepancy between the animal and human studies are the greater severity of ARF in human subjects and that secondary renal insults such as recurrent hypotension, drug toxicity and even dialysis occurred during this trial. The marked difference in mortality between the control and treatment groups may in part be due to patient selection for the trial. The retrospective study of mortality in ARF patients found a mortality of $60 \%$ compared to the rates of $43 \%$ and $13 \%$ in the treatment and control groups. The APACHE II scores of the trial patients were lower than those in the retrospective study. However, the groups in the study were well matched. The time from study entry to death was several weeks and did not differ between the two groups. This might suggest that a persistently low TSH may identify a subgroup of ARF patients with a higher mortality and also raises some questions about the apparent 'cause and effect' association between thyroxine administration and death.

\section{References}

1. Acker CG, Singh AS, Flick RP, Bernardini J, Greenberg A, Johnson JP: A trial of thyroxine in acute renal failure. Kidney Int. 2000, 57: 293-298. 